\title{
Effect of Oestrous-cycle Stage on the Response of Mares in a Novel Object Test and Isolation Test
}

\author{
Y Hedberg' ${ }^{1}$ A-M Dalin ${ }^{1}$, P Öhagen ${ }^{2}, K_{R}$ Holm $^{3}$ and H Kindahl ${ }^{1}$ \\ Divisions of ${ }^{1}$ Comparative Reproduction, Obstetrics and Udder Health, ${ }^{2}$ Epidemiology and Ruminant Medicine, and ${ }^{3}$ Large Animal Clinical Sciences, \\ Department of Clinical Sciences, Swedish University of Agricultural Sciences, Uppsala, Sweden
}

\begin{abstract}
Contents
In various species, sex, hormonal treatments and oestrouscycle stage have been shown to affect the animal's response in behavioural tests. Few such studies have been performed in the horse. The main aim of the present study was to investigate whether oestrous-cycle stage affects mares' response to a novel object test and isolation test and, in part, to study whether mares, assumed to suffer from oestrous-related behavioural problems, respond differently in these tests when compared with controls. Twelve mares were tested twice, in oestrus and dioestrus, in a crossover design. Seven behavioural and two heart rate variables were measured for the novel object test and two heart rate variables for the isolation test. Oestrous-cycle stage and whether a mare was classified as a 'problem' mare did not affect the mare's response. However, test order, i.e. the cycle stage a mare was tested in first, affected its reaction. This effect could partly be explained by significant differences between test occasions 1 and 2 in three behavioural variables and one heart rate variable $(\mathrm{p}<0.05)$ in the novel object test. The mares explored the novel object more and had a higher mean heart rate in the first test. Exploring the novel object more could largely be attributed to those mares tested in dioestrus first, perhaps indicating that the mares in oestrus were less receptive to the novel object. The reason for the differences between test occasions could be an effect of learning or habituation.
\end{abstract}

\section{Introduction}

Today, horses are widely used in sports and riding competitions and are often expected to perform at a high level. The athletic skill of the horse is obviously of importance, but the horse's disposition will also affect its ability to perform. If the personalities of the horse and rider do not match, performance may suffer (Morgan et al. 2000). The selection of horses for temperament is thus of great relevance and in recent years the use of behavioural tests to objectively describe the temperament of horses has emerged. The novel object test and novel environment test (open-field test) have been used in a variety of species, including the horse, to test for emotionality or fear (Vandenheede and Bouissou 1993; Spoolder et al. 1996; Wolff et al. 1997; Visser et al. 2001). The novel object test was performed in young and adult horses (Le Scolan et al. 1997; Wolff et al. 1997; Visser et al. 2001). In young horses, the behavioural variables in the tests were fairly consistent over time, suggesting that they can be regarded as the individual's response and not simply coincidence (Visser et al. 2001). Short-term social isolation has been used in other species, such as sheep, a herd-living animal like the horse. Such tests can be used to distinguish between various individuals displaying different levels of arousal elicited by the test situation (Manteca and Deag 1993).

By measuring the heart rate during behavioural tests, one can further differentiate individuals. In isolation tests performed in familiar surroundings, sheep which showed no physical or vocal distress could still be discriminated from each other using heart rate measurements (Syme and Elphick 1982/83). It has been found that an increase in the heart rate of horses is positively correlated with an increase in nervousness as measured by an emotionality score (McCann 1988).

If behavioural tests are to be used, they need to be reliable. For a behavioural variable to be considered part of a temperamental trait, that variable needs to be expressed consistently over time in identical test situations (within-test consistency). Sex differences and the effect of hormonal treatments have been studied as possible factors affecting the response in behavioural tests in various mammals, such as rats, chimpanzee and sheep (Archer 1975; Buirski et al. 1978; Vandenheede and Bouissou 1993). Differences in an animal's reaction in various test situations have been found not only to depend on gender, but also on oestrous-cycle stage (Burke and Broadhurst 1966; Quadagno et al. 1972; Diaz-Veliz et al. 1991). To our knowledge, no behavioural studies have been performed in the horse, where oestrous-cycle stage has been considered.

The principal aim of the present study was to evaluate if mares respond differently depending on oestrous cycle stage in two different behavioural test situations (a novel object test and isolation test). Moreover, an attempt was made to study whether mares, perceived by their owners to suffer from oestrous-cycle-related behavioural problems, react differently in behavioural tests when compared with controls. Owners often report that their mare's temperament seems to be affected by the oestrous-cycle stage. However, this is the owner's own interpretation and not based on scientific and clinical evaluation of the animal. Therefore, thorough clinical examinations and both subjective and objective behavioural studies are needed.

\section{Materials and methods}

All procedures were approved by the Ethical Committee for Experimentation with Animals, Sweden.

\section{Animals, housing and management}

The experiments were carried out between March and August 2003. Twelve mares, weighing between 250 and 
$600 \mathrm{~kg}$ and with an age span of 5-16 years, were included in the study. The breeds included were New Forest (1), Gotlandsruss (1), Swedish Warmblood (2), Swedish Standardbred (7) and Swedish Standardbred/ Warmblood cross (1). Seven of the mares were selected from a survey using questionnaires, which was conducted by the Department of Clinical Sciences. The survey included 38 mares (return-rate of $79 \%$ ) and was sent to owners who assumed that their mares suffered from oestrous-related behavioural problems. Inclusion criteria were behavioural problems perceived by the owner to be related to the oestrous phase of the cycle or very frequent/strong oestrous symptoms. In brief, the questionnaire contained questions related to the type of activities the mare was used for, type of feeding, stable and pasture environment, previous pregnancies, type of behavioural abnormality, association of the behavioural abnormality with the oestrous cycle and any treatment underwent by the mares. As the owners of the mares had to be willing to lend their mare to the clinic for a period of two complete oestrous cycles, it was not possible to apply random sampling on the survey population. The remaining five mares in the study were departmentowned and had no history of behavioural problems (controls).

During the experimental study, the mares were maintained at the Division of Comparative Reproduction, Obstetrics and Udder Health (Department of Clinical Sciences, Swedish University of Agriculture, Uppsala, Sweden). They were stabled on straw in individual loose boxes indoors during the night and let out during the day (approximately between 8.00 and 15.00 hours). The client-owned mares were kept in individual paddocks for safety reasons (approximately $10 \mathrm{~m} \times 20 \mathrm{~m}$ ), whereas the department-owned mares were kept together in a larger field on pasture. Apart from this, all mares were handled and managed in the same way by the handlers throughout the study. The mares were all fed the same diet consisting of grass hay (morning, noon and evening) and a small amount of oats and soaked sugar beet with a mineral supplement (afternoon). During the study period, the mares were followed up for at least two oestrous cycles and their daily behaviours carefully documented and related to oestrous cycle stage (subjective behavioural evaluation).

\section{Clinical examination}

Prior to testing, all mares were subjected to a thorough clinical examination. This was done to rule out that the riding difficulties or abnormal behaviour in the mares with a suspected oestrous-related problem were caused by a problem in the locomotory system. The clinical examination included a visual inspection of the horse and a careful palpation of the extremities and the back. The examination of the back was based on a study evaluating the back in clinically normal horses and performed by the same clinician as in that study (K.R. Holm, C. Johnston, C. Erichsen, P. Ehsell, unpubl. obs.). The horses were walked and trotted in a straight line on a hard surface, and flexion tests of the entire leg were performed in all four limbs. A thorough initial gynaecological examination was performed and blood and urine tests were conducted to rule out infections. Urinary tract infections can cause pollakiuria, which the owner may misinterpret as symptoms of oestrus. The blood parameters analysed were total white cell count and differential, fibrinogen, haemoglobin and haematocrit. Urine was sampled using a sterile catheter inserted into the urethra and applied onto a three-partitioned selective culture plate (SELMA, National Veterinary Institute, Uppsala, Sweden), which was incubated overnight at $37^{\circ} \mathrm{C}$, before being checked for bacterial growth. The mares of which the owners complained were difficult to ride or drive also had their teeth checked.

\section{Experimental study}

For control of oestrous symptoms, teasing with a stallion was performed twice daily - in the morning before being let out and in the afternoon when brought in. Oestrous signs were scored as follows: +1 for standing, +1 for flashing clitoris/urination, +1 for raising tail, -1 for kicking, -1 for switching tail and -1 for ears back. Mares were considered to be in oestrus if they displayed at least two positive signs. The behavioural tests were part of a larger study of mares with oestrous-related behavioural problems, resulting in the mares being followed up from 1 to 6 weeks prior to testing. One control mare was not followed up before testing began, but it was a department-owned mare known to have a normal oestrous cycle length according to daily oestrous records. The mares were subjected to rectal examination of the uterus and ovaries using transrectal ultrasound (six $\mathrm{MHz}$ linear probe, 485 Anser; Pie Medical, Maastricht, the Netherlands) every other day during oestrus (to control follicular development as well as ovulation) and every fourth day during the luteal phase. Oedema in the uterus was graded as follows: grade 1 indicated a heterogenic appearance, but no defined endometrial folds; grade 2 indicated an increase in heterogenicity with some endometrial folds visible; and grade 3 indicated extreme heterogenicity with large anechoic areas. Blood samples were collected daily for, when possible, 3 weeks prior to testing until 1 week after the last test and analysed for progesterone content. For technical reasons as well as restricted access to client-owned horses, six mares were sampled for less than that period. Blood samples on the test days were also analysed for oestradiol content. One mare was not blood-sampled on its test day in oestrus, for technical reasons.

\section{Hormone analyses}

Hormone analyses were performed at the Division of Clinical Pathology (Department of Biomedical Sciences and Veterinary Public Health, Swedish University of Agricultural Sciences, Uppsala, Sweden).

The concentration of progesterone in peripheral blood plasma was determined using a solid-phase radioimmunoassay (Coat-a-Count Progesterone; Diagnostic Products Corporation, Los Angeles, CA, USA). The kit was used according to the manufacturer's instructions. The relative cross-reactions of the antibody 
were $0.9 \%$ with corticosterone, $0.03 \%$ with cortisol and $0.1 \%$ with testosterone. The inter- and intra-assay coefficients of variation for progesterone were as follows: 4.1 and $8.8 \%$ at $3.5 \mathrm{nmol} / 1 ; 7.1$ and $5.4 \%$ at $22.2 \mathrm{nmol} / \mathrm{l} ; 8.7$ and $5.8 \%$ at $46.8 \mathrm{nmol} / 1 \mathrm{respectively.}$ The minimum detectable concentration of progesterone was $0.1 \mathrm{nmol} / 1$.

The concentration of oestradiol-17 $\beta$ was determined by radioimmunoassay using a DPC kit (Diagnostic Products Corporation), as reported for use in bovine plasma (Sirois and Fortune 1990). The intra-assay coefficient of variation was as follows: $10.8 \%$ at $2.3 \mathrm{pmol} / 1, \quad 11.4 \%$ at $37.2 \mathrm{pmol} / 1$ and $17.0 \%$ at $123.2 \mathrm{pmol} / 1$. The minimum detectable concentration of oestradiol- $17 \beta$ was $1.1 \mathrm{pmol} / 1$.

\section{Behavioural test procedure}

The tests were carried out twice for each mare - once in oestrus and once in the luteal phase (dioestrus). At least 1 month elapsed between the two tests, except for one mare where the tests were performed only 11 days apart. This was because the mare was client-owned and not available at the department for a longer period. A crossover design was used with the mares randomly assigned to a test order. A mare was said to be in oestrus if it had a follicle larger than $3 \mathrm{~cm}$ in diameter, oedema in the uterus and/or showed behavioural oestrus when teased with a stallion. Behavioural oestrus was not deemed necessary, as one of the mares tended to show silent oestrus. Two mares were given an injection of $1 \mathrm{ml}$ of prostaglandin $\mathrm{F}_{2 \alpha}\left(\right.$ Dinolytic $^{\circledR}$ vet; Orion Pharma $\mathrm{AB}$, Animal Health, Sollentuna, Sweden) $(5 \mathrm{mg} / \mathrm{ml})$ intramuscularly to induce oestrus. The tests in the luteal phase were carried out between days 5 and 12 postovulation when the concentration of progesterone was presumed to be high (Ginther 1992). All of the tests were carried out between 10.00 and 16.00 hours. Before the test, the equipment used for registration of heart rate was applied (for details, see Data Acquisition). A 3-min baseline recording of the resting heart rate was taken with the horse in its box with at least one companion animal in an adjacent box.

\section{Isolation test}

This test was always performed prior to and on the day of the novel object test. In the isolation test, the mare was alone in its box and in the stable unit for $3 \mathrm{~min}$, unable to see or hear another horse. This test was not video-recorded; only heart-rate recordings were taken.

\section{Novel object test}

The test procedure was based on a model used by Visser et al. (2001), with some minor modifications. The mares were habituated to the testing procedures by a familiar handler walking the mares individually to the testing arena $(10.7 \mathrm{~m} \times 11.6 \mathrm{~m})$ and letting them loose in the arena for $10 \mathrm{~min}$, twice before each test occasion.

On the day of the test, a handler familiar to the mare led it to the test arena and let it loose. The mare's behaviour throughout the test was recorded using a videotape recorder, operated by a person out of view from the horse. Two minutes after the horse had been let loose in the arena, the novel object (a yellow inflated ball, $55 \mathrm{~cm}$ in diameter) was lowered from the ceiling, from a height of approximately $4 \mathrm{~m}$. An extra weight $(3.7 \mathrm{~kg})$ was attached to the object to ensure that it immediately hit the ground after being released. Prior to testing, a circle around the hit point with a diameter of $2 \mathrm{~m}$ was marked on the ground. The horse was left in the arena for an additional $5 \mathrm{~min}$ with the object, after which it was brought back to its box. Heart rate was registered throughout the test.

\section{Data acquisition}

Heart rate was recorded using Polar Vantage (Polar Electro OY, Kempele, Finland), consisting of two electrodes, a transmitter and a wristwatch receiver. An elastic surcingle was placed around the girth of the mare, just caudal to the front legs, to which the electrodes and transmitter were attached. Water was used to enhance contact between the electrodes and the skin. The receiver was placed in a pocket attached to the surcingle and was set to record the instantaneous heart rate every $5 \mathrm{~s}$. In three of the mares (two 'problem' mares and one control), because of rolling on the ground or exuberant behaviour in the novel object test, the electrodes failed to properly register the heart rate.

In the novel object test, six behavioural variables were measured as percentage of total test time and one variable, as a frequency (Table 1). For each horse, the video recordings from the novel object test were analysed using a stopwatch to determine the amount of time in seconds for each behavioural variable. These data were then re-calculated as a percentage of the total test time. The frequency of snorting was calculated as the number of times the mare snorted during the total test time. The heart rate recordings were loaded into a computer using an interface device (Polar IR Interface $^{\mathrm{TM}}$, Polar Electro OY). Using the Polar Equine Software 3.0 program(Polar Electro Europe BV, Fleurier, Switzerland), heart rate curves for each mare

Table 1. Behavioural variables recorded in the novel object test (modified from Visser et al. 2001)

\begin{tabular}{|c|c|c|}
\hline Behavioural variable & Abbreviation & Definition \\
\hline Snorting ${ }^{\mathrm{a}}$ & Snort & Forceful expulsion of air \\
\hline Exploring object ${ }^{\mathrm{b}}$ & Expo & $\begin{array}{l}\text { Eyes, ears and head pointed } \\
\text { towards object, nose below belly line } \\
\text { and horse within } 2 \mathrm{~m} \text { of object }\end{array}$ \\
\hline Exploring other ${ }^{\mathrm{b}}$ & Expoth & $\begin{array}{l}\text { Eyes, ears and head pointed forwards } \\
\text { but not towards object, nose below } \\
\text { belly line and horse not within } \\
2 \mathrm{~m} \text { of object }\end{array}$ \\
\hline Focused on object ${ }^{\mathrm{b}}$ & Foc & $\begin{array}{l}\text { Eyes, ears and head pointed } \\
\text { towards object }\end{array}$ \\
\hline Latency to enter circle ${ }^{b}$ & Latcirc & $\begin{array}{l}\text { Latency to come within } \\
2 \mathrm{~m} \text { of object }\end{array}$ \\
\hline $\begin{array}{l}\text { Latency to touch } \\
\text { object first time }\end{array}$ & Lattou & \\
\hline Trotting or cantering ${ }^{\mathrm{b}}$ & $\mathrm{Tr} / \mathrm{Ca}$ & \\
\hline
\end{tabular}

${ }^{\mathrm{a}}$ Frequency.

${ }^{\mathrm{b}}$ Percentage of total test time. 
in each test were saved in the computer and analysed later. The mean and maximum heart rates were calculated as the mean and maximum heart rates recorded in each test subtracted by the mean heart rate during the basal recording.

\section{Statistical analysis}

Statistical analyses were calculated using Minitab $^{\circledR}$ Release 14.11. Non-parametric statistical tests were chosen because of the low number of animals in the study. Wilcoxon signed rank confidence interval was used to test the difference between the oestrus and dioestrus value for each variable. Efficacy variable was defined as either the percentage of total test time a behavioural variable was displayed (all behavioural variables in the novel object test except 'snorting'), the number of times during the test a variable was expressed ('snorting' in the novel object test) or maximum/mean change in heart rate from the mean baseline heart rate. To determine the effect of a mare being a 'problem' mare, analysis of variance (GLM procedure) was calculated for each variable where the response variable was the difference between the oestrus and dioestrus value for each variable and the model variable was either 'problem' mare or 'control' mare. The same procedure was then used to calculate the effect of test order of how the mares reacted in the tests (the model variable for test order was 'oestrus first' or 'dioestrus first'). For two of the behavioural variables in the novel object test (exploring the object and latency to touch the object) there was a significant effect of test order $(\mathrm{p}<0.05)$ and for one behavioural variable, a tendency to effect of test order (latency to enter the $2 \mathrm{~m}$ circle) $(\mathrm{p}=0.06)$. That is, which oestrous-cycle stage a mare was tested in first affected its response in these three behavioural variables. Therefore, the mares were divided into two groups: those tested in dioestrus first and those tested in oestrus first. One-sample Wilcoxon test was then used to test the median (median not equal to 0 ) for the difference between the values in oestrus and dioestrus for each group. In addition, to evaluate if the effect of test order was, in part, due to differences between test occasion (i.e. an effect of learning or habituation), one-sample Wilcoxon non-parametric test was used, testing the median (median not equal to 0 ) of the difference between the values in tests 1 and 2 for each variable studied.

\section{Results}

\section{Questionnaire results}

The histories of the 'problem' mares were different for each mare. According to the survey, five of the seven 'problem' mares would urinate and lift their tail frequently (mares An, C, W, F and Be). Such behaviours are normal symptoms of oestrus, but may be considered abnormal by the owner. Five mares would often refuse to move forward, either while ridden or being led (mares An, C, W, F and Z). Three mares were described as aggressive and would bite and/or kick (mares W, F and $\mathrm{Z}$ ). Other behaviours that were described were pressing against handler and bucking/rearing while ridden (mares
An and $\mathrm{W}$ ). Three mares were said to display the abnormal behaviour more or less all the time (mares $\mathrm{C}$, $\mathrm{F}$ and $\mathrm{Z}$ ); one of these mares was better after foaling when it was lactating (mare Z). Another mare would show strong oestrous behaviour, but only in association with competition (trotting races) (mare $\mathrm{Be}$ ). However, the owners still claimed that the oestrous cycle was to blame for these behaviours. During the experimental period at the clinic, only three mares showed abnormal behaviour. One mare (Be) showed extremely intense oestrous signs where it continually winked its clitoris and stood in a urinating stance when in oestrus. While these behaviours are normal oestrous signs, it is of the authors' opinion that this mare showed stronger signs than usually seen in the majority of mares. The two other 'problem' mares showed different behavioural abnormalities, which were always associated with the oestrous phase of the oestrous cycle. One mare screamed and hit its hind-end on the box wall in oestrus, especially after teasing (mare Ev) and the other mare pressed against the handler, refused to move forward and showed oestrous signs more frequently towards the handler than the stallion (mare An).

\section{Clinical examination and blood/urine samples}

All horses in the study were considered to be in a good general condition, symmetrically and normally muscled. No horse showed any painful reaction to back palpation. All horses were sound at trot on a straight line on a hard surface, although minor reactions to one or more flexion tests were seen in all horses. No sign of infection was detected in any of the blood or urine samples. At gynaecological examination, all mares were found to have ovarian cyclicity, with no pathological findings.

During the study period, one mare suffered from a wound to the poll, which led to a delay of the second behavioural test. Another mare developed a cough and nasal discharge, but no fever, during the experimental period. A bacteriological swab taken from the nostril of the mare was negative. She was not tested during this time.

\section{Oestrous detection scores and gynaecological findings}

The number of positive and negative oestrous signs for each mare is presented in Table 2. The mean oestrous detection score of the mares in oestrus was +2 (range 0 to +3$)$. One of the mares with a score of 0 showed silent oestrus (mare F). She was in fact a mare claimed by her owner to show strong oestrous signs. The other two mares received a score of 0 because of displaying both positive and negative signs (mares Ev and Ex). The mean oestrous detection score of the mares in dioestrus was -1.25 (range -3 to +1 ). The mare with a positive score always lifted its tail when presented to the stallion, but when in oestrus showed clear clitoral winking and urination (mare An). The criteria used when testing was performed in oestrus resulted in all of the mares being tested on the first or second day of behavioural oestrus, except for one mare (day 4) (see Table 2). As mentioned above, one mare showed no behavioural oestrus. On the oestrous test day, the mares had an average of grade 1.8 oedema in the uterus (range of grade 1-3). However, 
Table 2. Number of positive and negative oestrous detection signs and plasma concentrations of progesterone (P4) and oestradiol 17- $\beta$ (E2) in oestrus and dioestrus on test days

\begin{tabular}{|c|c|c|c|c|c|c|c|c|c|}
\hline \multicolumn{2}{|c|}{ Oestrous phase } & \multicolumn{4}{|c|}{ Oestrus } & \multicolumn{4}{|c|}{ Dioestrus } \\
\hline Mare & Day in oestrus & No. pos. signs & No. neg. signs & $\mathrm{P} 4(\mathrm{nmol} / \mathrm{l})$ & $\mathrm{E} 2(\mathrm{pmol} / \mathrm{l})$ & No. pos. signs & No. neg. signs & $\mathrm{P} 4(\mathrm{nmol} / \mathrm{l})$ & $\mathrm{E} 2(\mathrm{pmol} / \mathrm{l})$ \\
\hline $\mathrm{An}^{\mathrm{a}}$ & 1 & 3 & 0 & 1.0 & 41 & 1 & 0 & 27.0 & 18 \\
\hline $\mathrm{Be}^{\mathrm{a}}$ & 4 & 3 & 0 & 0.0 & 24 & 0 & 0 & 59.6 & 9 \\
\hline $\mathrm{W}^{\mathrm{a}}$ & 2 & 2 & 0 & 1.0 & 35 & 0 & 1 & 21.2 & 8 \\
\hline $\mathrm{F}^{\mathrm{a}}$ & $?$ & 0 & 0 & 3.6 & 8 & 0 & 0 & 37.0 & 5 \\
\hline $\mathrm{Z}^{\mathrm{a}}$ & 1 & 3 & 0 & 0.5 & 25 & 0 & 1 & 20.7 & 25 \\
\hline $\mathrm{C}^{\mathrm{a}}$ & 1 & 3 & 1 & 0.5 & 30 & 0 & 3 & 26.4 & 8 \\
\hline$E v^{a}$ & 1 & 3 & 2 & 0.5 & 17 & 1 & 2 & 41.6 & 6 \\
\hline $\mathrm{B}^{\mathrm{b}}$ & 2 & 3 & 0 & 0.5 & 40 & 0 & 2 & 26.4 & 13 \\
\hline $\mathrm{A}^{\mathrm{b}}$ & 1 & 3 & 0 & 0.4 & 18 & 0 & 1 & 34.8 & 15 \\
\hline $\mathrm{Ex}^{\mathrm{b}}$ & 1 & 2 & 2 & 0.8 & 7 & 0 & 2 & 95.5 & 12 \\
\hline $\mathrm{M}^{\mathrm{b}}$ & 2 & 3 & 0 & 0.5 & 25 & 0 & 2 & 27.1 & 30 \\
\hline $\mathrm{O}^{\mathrm{b}}$ & 2 & 3 & 0 & $\mathrm{~N} / \mathrm{A}$ & $\mathrm{N} / \mathrm{A}$ & 0 & 2 & 47.2 & 5 \\
\hline
\end{tabular}

a'Problem' mare.

${ }^{\mathrm{b}}$ Control mare.

$\mathrm{N} / \mathrm{A}=$ not available.

$?=$ showed no behavioural oestrus

data for two mares were not known; one mare was palpated rectally but not examined with ultrasound on the test day because of irritation of the intestinal mucosa. Another mare showed behavioural oestrus, but was not examined rectally or with ultrasound in conjunction with the test, for technical reasons. The average size of the largest follicle on the test day in oestrus was $3.8 \mathrm{~cm}$ (range $3.4-5.0 \mathrm{~cm}$ ). One mare's follicle size was not known (see above).

\section{Hormone concentrations}

The daily samples confirmed that all mares were cycling normally during the experimental period. One 'problem' mare (mare $\mathrm{Be}$ ) had an oestrous period of 17 days in its first cycle. This was, however, considered within normal limits for the time of year (March). Another 'problem' mare (mare C) developed a persistent corpus luteum and was thus injected with prostaglandin $\mathrm{F}_{2 \alpha}$ (Dinolytic ${ }^{\circledR}$ vet) on the $23 \mathrm{rd}$ day of dioestrus. Table 2 shows the plasma hormone concentrations in the 'problem' mares and controls on each test occasion. As a result of high individual variation, the hormonal concentrations are presented for each mare. All mares had progesterone concentrations above $20 \mathrm{nmol} / \mathrm{l}$, when tested in the luteal phase, with a mean plasma progesterone concentration of $38.7 \mathrm{nmol} / 1$ (SD $=21.2 \mathrm{nmol} / 1)$. In oestrus, the plasma level of progesterone was in all mares except one $\leq 1 \mathrm{nmol} / 1$, with a mean plasma progesterone concentration of $0.8 \mathrm{nmol} / 1(\mathrm{SD}=1.0 \mathrm{nmol} / \mathrm{l})$. Oestradiol$17 \beta$ concentrations were more varied; in oestrus, the mean value of oestradiol-17 $\beta$ was $24.5 \mathrm{pmol} / 1$ (SD = $11.5 \mathrm{pmol} / \mathrm{l}$ ) and in dioestrus the mean value was $11.7 \mathrm{pmol} / 1$ (SD $=7 \mathrm{pmol} / \mathrm{l})$. Two mares had oestradiol- $17 \beta$ concentrations below $10 \mathrm{pmol} / 1$ on the oestrous test day. One of the mares with a low concentration ( $8 \mathrm{pmol} / \mathrm{l})$ showed silent oestrus (oestrous detection score of 0 ), despite having follicles above $4 \mathrm{~cm}$ in diameter and oedema in the uterus. The second mare showed full oestrus but ovulated the next day. In dioestrus, all the mares except one had oestradiol-17 $\beta$ concentrations below $20 \mathrm{pmol} / 1$. One mare had an oestradiol- $17 \beta$ concentration of $30 \mathrm{pmol} / 1$, which may have been due to a dioestrous follicle, $3.8 \mathrm{~cm}$ in diameter (oestrous detection score of -2 ).

\section{Behavioural and heart rate variables}

The results of the behavioural and heart rate variables for the novel object tests and isolation tests in oestrus and dioestrus are shown in Fig. 1a,b. No behavioural variables or heart rate scores differed according to stage of oestrous cycle. There were also no significant differences in any of the measured variables in either test between 'problem' mares and controls (Fig. 2a,b). However, one 'problem' mare (mare F), described by its owner as reluctant to leave other horses in the stable when in oestrus, had a very high maximum heart rate in its isolation test in oestrus (120 beats per minute above basal value, compared with 18 beats per minute above basal value in dioestrus).

In the novel object test, there was a significant effect of test order for exploring object $(\mathrm{p}<0.05)$, latency to touch the object $(\mathrm{p}<0.05)$ and a tendency to an effect of test order for latency to enter circle $(p=0.06)$. In the separate groups, the mares that were tested in dioestrus first tended to touch the novel object earlier in the first test $(\mathrm{p}=0.06)$, whereas no significant differences could be found between test occasions with the mares tested in oestrus first.

For all mares, the mares explored the object more, as well as entered the circle and touched the object earlier on the first test occasion when compared with the second $(p<0.05)$ (Fig. 3a). The mares also had a significantly higher mean heart rate in the first test $(\mathrm{p}<0.05)$ (Fig. 3b).

\section{Discussion}

Behavioural tests are frequently used in an attempt to compare individuals in a standardized manner and often measure reactions to a change in the environment, which 


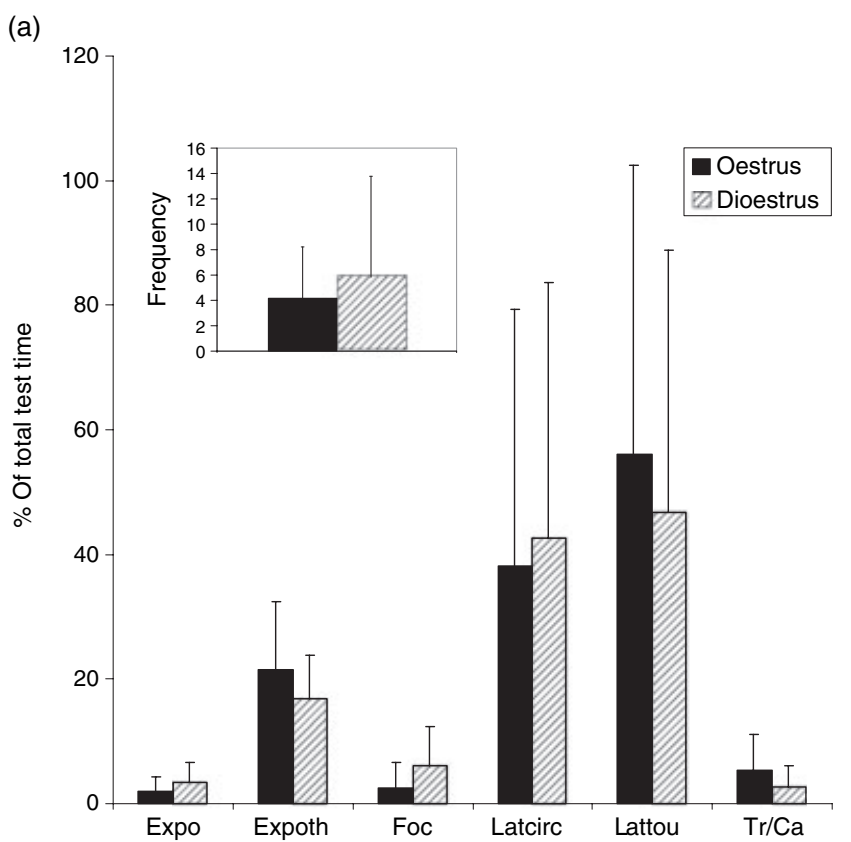

(b)

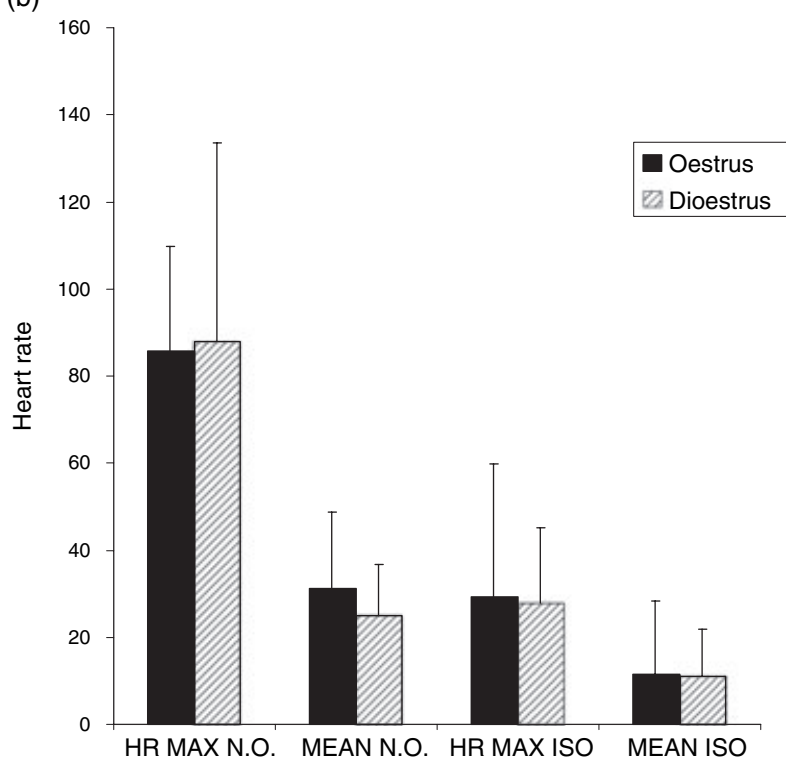

Fig. 1. (a) Mean (SD) percentage of total test time of behavioural variables and mean (SD) frequency of snorting (inset) in the novel object test in oestrus and dioestrus; (b) mean and maximum (SD) heart rates in the novel object test and isolation test in oestrus and dioestrus. HR MAX: maximum change from baseline heart rate; HR MEAN: mean change from baseline heart rate; N.O.: novel object test; ISO: isolation test. For abbreviations of behavioural variables, see Table 1

may reflect certain temperamental traits in an individual. Temperament has been referred to as 'the way in which individuals react to environmental change and challenge' (Lawrence et al. 1991). One aspect of temperament, emotionality, sometimes referred to as fearfulness, can be seen as 'a basic psychological characteristic of an individual that predisposes it to perceive and react in a similar manner to a wide range of potentially frightening events' (Boissy 1995). Recently, the broader concept of 'personality' in the horse has been developed to include various mental aspects such
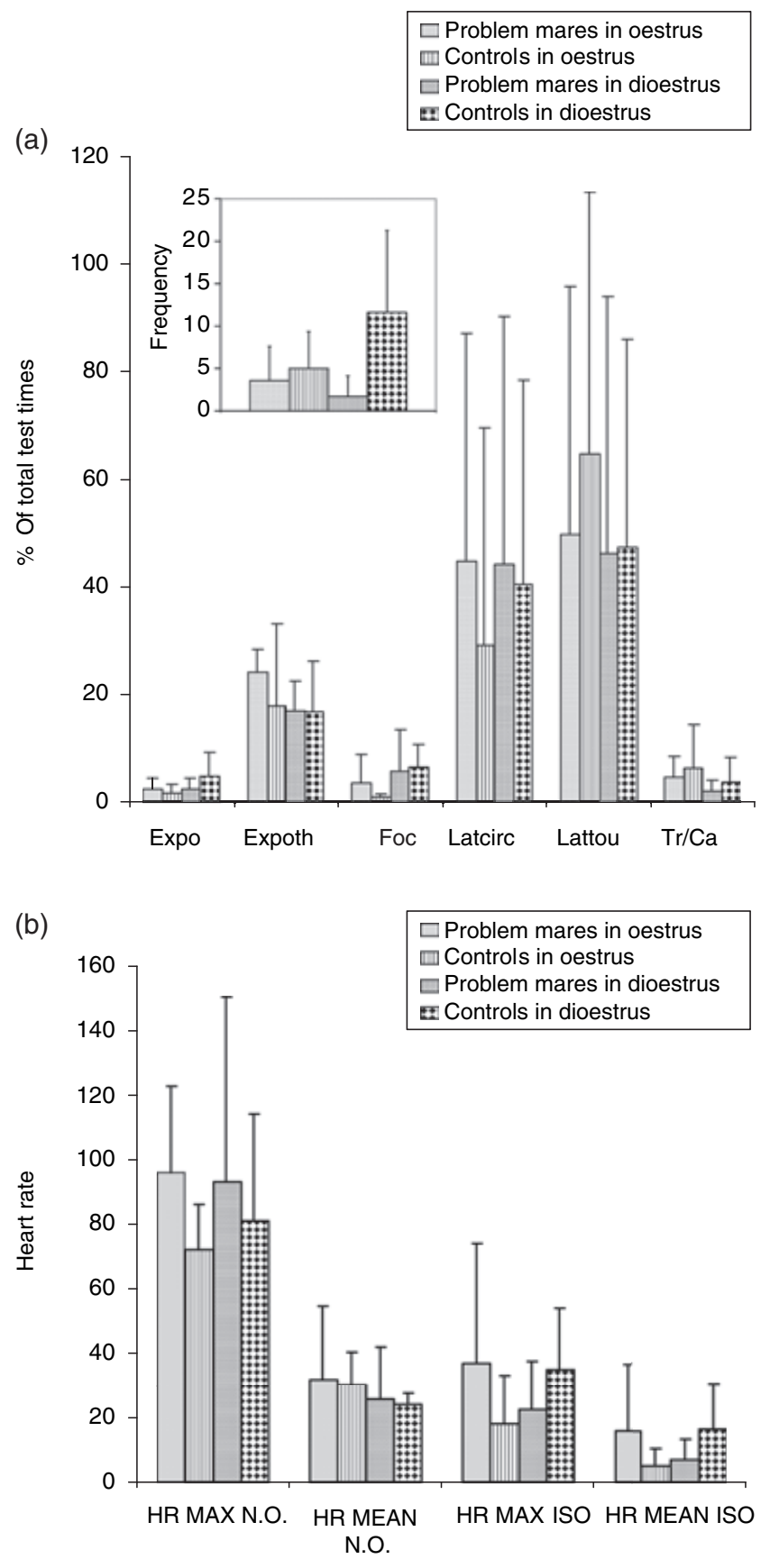

Fig. 2. (a) Mean (SD) percentage of total test time of behavioural variables and mean (SD) frequency of snorting (inset) in the novel object test for 'problem' mares and controls in oestrus and dioestrus; (b) mean and maximum (SD) heart rates in the novel object test and isolation test for 'problem' mares and controls in oestrus and dioestrus

as temperament, reactivity to man and learning abilities (Visser 2002).

Furthermore, it has been shown that sex steroids are involved in behaviours other than sexual behaviour in some species. For example, in rats, oestradiol seems to stimulate general motor activity (Diaz-Veliz et al. 1991) and has been shown to increase ambulation of rats in oestrus in open-field tests (Quadagno et al. 1972). In the present study, the mares trotted and cantered more in oestrus than in dioestrus, but this difference was not significant. 
(a)

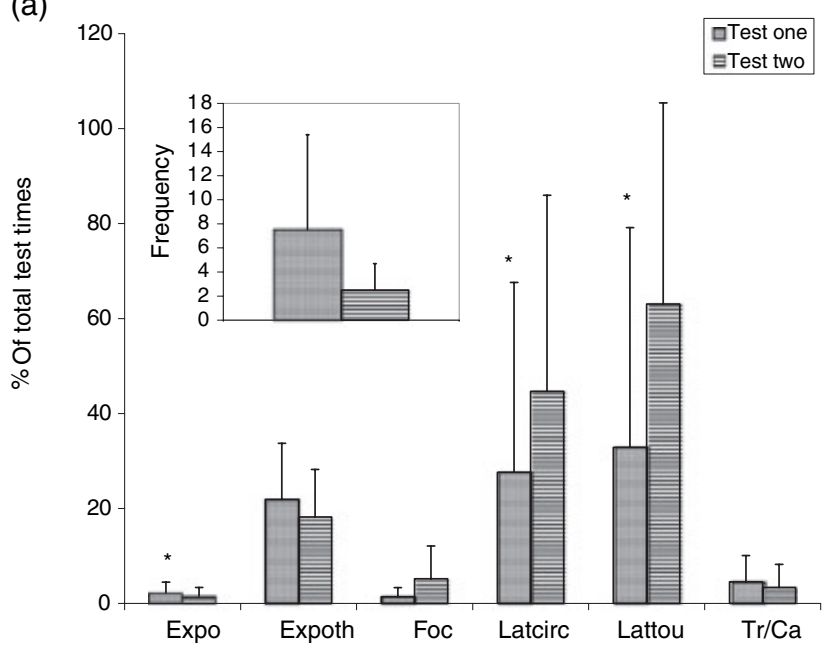

(b)

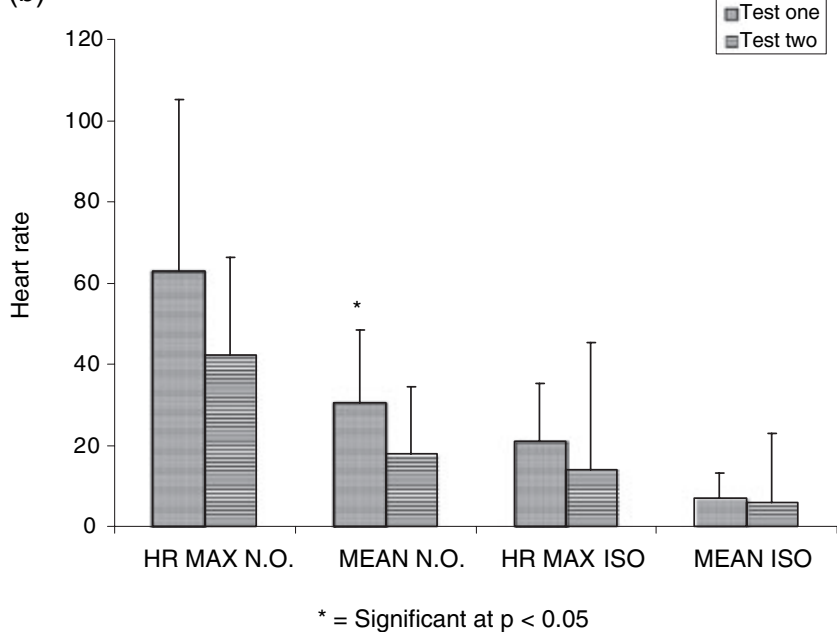

Fig. 3. (a) Mean (SD) percentage of total test time of behavioural variables and mean (SD) frequency of snorting (inset) in the novel object test in tests 1 and 2; (b) mean and maximum (SD) heart rates in the novel object test and isolation test in tests 1 and 2

Wolff et al. (1997) found no differences according to sex when horses were tested in a novel object test, but stage of oestrous cycle of the mares was not considered. However, there seems to be a common notion that the temperament of mares is less stable than that of geldings, and therefore may be more difficult to use for competition purposes. According to one study of Swedish Warmblood horses, the majority of horses used in advanced dressage and show jumping classes are geldings or stallions $(100 \%$ of the dressage horses and $75 \%$ of the showjumpers in the study material) (Holmström and Philipsson 1990). Until a ban against longacting progesterone treatment was introduced in the European Community countries, progesterone treatment in competition mares displaying strong and/or lengthy oestrous symptoms was widely used (Taugbøl et al. 1991; Lindström 2000). Evidence suggests that progestational therapy has a 'tranquilizing antiandrogenic and antiestrogenic effect in nervous, hypersexual stallions and mares' (Roberts and Beaver 1987). Moreover, pregnant mares are often more relaxed and placid than their non-pregnant counterparts (Roberts and Beaver 1987).

In the present study, however, no behavioural variables or heart rate scores differed significantly according to the stage of the oestrous cycle. It seems, then, that the hormonal fluctuations that occur during the oestrous cycle of the mare have no effect on reactions in a novel object test and isolation test. Such behavioural tests should, therefore, be reliable indicators of temperament regardless of when in the oestrous cycle a mare is tested. Even including mares where the owners assumed their behaviour to be varied in some manner according to the oestrous cycle stage did not reveal an effect of cycle stage in the objective behavioural tests. It has to be stressed, however, that the number of animals used in the study was low and differences may have gone undetected. Moreover, the effect of test order indicates that oestrous cycle stage to some extent did affect the response; i.e. a mare being tested in dioestrus first may have responded in a different manner when compared with if that same mare had been tested in oestrus first. The mares tested in dioestrus first tended to explore the novel object more in the first test as compared to the second, perhaps indicating that they were more receptive to the object than the mares tested in oestrus first, where no such differences could be found. However, because of the effect of test order, a crossover design may not have been the best model to use. A matched-pair test may have been more appropriate, although such a design is likely to entail confounding factors as matching of the mares used in the study would have proven difficult. Using two different novel object tests, where the same mare can be tested in different test orders, may be helpful.

A secondary aim of the present study was to assess if mares, assumed by their owners to have behavioural abnormalities associated with the oestrous cycle, can be evaluated using objective behavioural tests. It has been suggested that exaggerated oestrous signs may be caused by an activation of the hypothalamo-pituitary-adrenal axis and an aberrant production of adrenal hormones (Roberts and Beaver 1987). Thus, mares with strong oestrous behaviour may experience a greater stress or emotionality level during the oestrous phase of the cycle when compared with dioestrus and/or mares with more normal oestrous behaviour. However, as the majority of these mares did not show any behavioural abnormalities during the subjective behavioural evaluation, the misinterpretation of the animals by their owners is likely. The theory of greater emotionality in mares with true behavioural disturbances could thus not be confirmed in the present study and it is not surprising that there were no significant differences in any of the measured variables (heart rate and behaviour) between 'problem' mares and controls, clinical examination included (Fig. 2a,b). To rule out possible causes of oestrousrelated behavioural problems, it is vital to clinically examine such mares and study their behaviour. In the present study, thorough clinical examination and blood/ urine tests excluded disturbances in the locomotory system and infections as possible causes of the mares' disturbed behaviours. For instance, the major complaint in the history of horses with back problems is impaired 
performance and/or altered behaviour, which could be confused with the history of the mares in the study. Subjective behavioural evaluation of the mares during the study period revealed that only three mares displayed somewhat exaggerated oestrous behaviour. This may be due to the owners misinterpreting their mare's behaviour or may reflect a strong environmental cause for the disturbed behaviour. As already mentioned, the 'problem' mares were selected according to the owner's perception of their mare's behaviour and both the 'problem' mares' histories and behaviours displayed during the study period differed from one another. The results of the clinical examination and behavioural testing seem to imply that many owners interpret their mare's normal oestrous behaviour as abnormal. Client education in the mare's normal oestrous behaviour is therefore considered of great importance when dealing with oestrous-related behavioural problems. The question arises as to what extent true nymphomania exists in the mare and what in fact is owner ignorance and/or environmental and handling influences of the animal. This should be further studied.

The 'problem' mares did not react differently from controls in the isolation test. However, interestingly, one 'problem' mare had a very high maximum heart rate in its isolation test in oestrus when compared with her test in dioestrus (mare F). The difference in heart rate was not an effect of habituation to the test procedure, as the mare was tested in dioestrus first. Its owner's major complaint according to the questionnaire was a strong reluctance to move away from other horses in the stable when in oestrus. Horses are gregarious animals and separation from other horses in arena tests has been used for checking emotionality (Wolff et al. 1997). In addition, oestrous behaviour has been suggested to be a means of strengthening the bond between mares and stallion in a herd (Asa et al. 1980). Thus, some mares with exaggerated oestrous behaviour may also be more gregarious than other mares.

Notably, three behavioural variables and one heart rate variable differed significantly between test occasions 1 and 2 (Fig. 3a,b). The reason for this could be an effect of learning or habituation. Horses habituate relatively quickly to stimuli that do not resemble naturally occurring dangers (Voith 1986). The time between the two test occasions may have been too short, although at least a gap of 1 month was used in the present study. Repeatedly exposing a horse to a stimulus that does not lead to any consequence results in a decrease or cessation of its response (Voith 1986). However, Visser et al. (2001) found short-term consistency in almost all the behavioural variables between tests performed 1 month apart. Longer time between test occasions was not possible in this study, because client-owned mares were used and because of the seasonal breeding nature of the mares. In the present study, the mares explored the object significantly more and entered the $2-\mathrm{m}$ circle and touched the object significantly earlier in test 1 when compared with test $2(\mathrm{p}<0.05)$. This seems to indicate that the object had lost some of its novelty in the second test and the mares were thus not as interested in exploring it as in test 1 . This is in contrast with Visser et al. (2001), who found that the horses tended to touch the object earlier over time. The horses in their study also explored the object significantly more in the second test. The reason for these differences may be due to an effect of age. The horses in the study of Visser et al. (2001) were all youngsters and perhaps more fearful, and this fear decreased with test number, whereas the mares in the present study were all mature and not as fearful, but perhaps more inquisitive in nature, and this decreased with test number as the object became familiar.

The mares in the present study had a significantly higher mean heart rate in the first test when compared with the second test $(p<0.05)$. Heart rate depends on the net effect of both the parasympathetic and sympathetic nervous systems. Depending on the type of stressor, there is a shift towards either a sympathetic or parasympathetic dominance. Individuals with a high parasympathetic activity (and a lower heart rate) would be expected to be more attentive, less easily distracted and better at adapting to environmental challenges (Friedman and Thayer 1998). An increase in heart rate reflects a shift towards sympathetic dominance and, in horses, seems to indicate a rise in nervousness (McCann 1988). Thus, the mares in the present study did seem to experience an increased level of nervousness in the first test. This, however, did not prevent them from exploring the object.

Reactions in a novel object test in young horses have been used to assess flightiness and sensitiveness. Horses showing high levels of these traits were assumed to be the most fearful (Visser et al. 2001). Wolff et al. (1997) also showed that in young horses, the novel object test seems to measure the level of fear. However, in one study of mature horses (3-17 years old) the novel object test was found to correlate better with riders' ratings of nervousness than fearfulness (Le Scolan et al. 1997). In the present study, all mares were mature and seemed to display some nervousness (increased heart rate) rather than fearfulness (explored and approached the object readily). Thus, the age of the horses studied seems to be important when evaluating the novel object test. Furthermore, when using mature horses, it may be necessary to prolong the interval between test occasions to try to avoid habituation to the test procedure.

In conclusion, the stage of the oestrous cycle a mare was in did not significantly affect the mare's reaction to a novel object or to isolation from other horses. However, the testing of a mare in dioestrus or oestrus first (test order) influenced the outcome of the tests, which may have masked a difference between oestrous cycle stage. The heterogenicity of the group of 'problem' mares is a factor that most likely influenced the results. Further studies using a larger number of animals and a modified test model are needed to evaluate the effect of oestrous cycle stage, particularly as the mares in our study seemed to habituate to the test procedure.

\section{Acknowledgements}

We are grateful to Marie Wallbring, Carola Jansson and Ulrika Mattsson for taking care of the mares, to Åsa Karlsson and Mari-Anne Carlsson for assistance with the hormone analyses and to the Swedish Racing and Totalisator Board (ATG) for financial support. 


\section{References}

Archer J, 1975: Rodent sex differences in emotional and related behaviour. Behav Biol 14, 451-479.

Asa CS, Goldfoot DA, Garcia MC, Ginther OJ, 1980: Sexual behaviour in ovariectomized and seasonally anovulatory mares. Horm Behav 14, 46-54.

Boissy A, 1995: Fear and fearfulness in animals. Q Rev Biol 70, 165-191.

Buirski P, Plutchik R, Kellerman H, 1978: Sex differences, dominance and personality in the chimpanzee. Anim Behav 26, 123-129.

Burke AW, Broadhurst PL, 1966: Behavioural correlates of the oestrous cycle in the rat. Nature (London) 209, 223-224.

Diaz-Veliz G, Urrest F, Dussaubat N, Mora S, 1991: Effects of estradiol replacement in ovariectomized rats on conditioned avoidance responses and other behaviors. Physiol Behav 50, $61-65$.

Friedman BH, Thayer JF, 1998: Autonomic balance revisited: panic anxiety and heart rate variability. J Psychiatr Res 44, $133-151$.

Ginther OJ, 1992: Endocrinology of the ovulatory season. In: Ginther OJ (ed.), Reproductive Biology of the Mare: Basic and Applied Aspects 2nd edn. Equiservices, Cross Plains, WI, pp. 238.

Holmström M, Philipsson J, 1990: Variation in conformation of Swedish Warmblood horses and conformational characteristics of élite sport horses. Equine Vet J 22, 186-193.

Lawrence AB, Terlouw EMC, Illiys AW, 1991: Individual differences in behavioural responses of pigs exposed to nonsocial and social challenges. Appl Anim Behav Sci 30, 7386.

Le Scolan N, Hausbegrer M, Wolff A, 1997: Stability over situations in temperamental traits of horses as revealed by experimental and scoring approaches. Behav Proc 41, 257266.

Lindström C, 2000: Nymphomania in the Mare. Master thesis, Faculty of Veterinary Medicine, Swedish University of Agriculture, Uppsala, pp. 11.

Manteca X, Deag JM, 1993: Individual differences in temperament of domestic animals: a review of methology. Anim Welfare 2, 247-268.

McCann JS, 1988: Normal and more highly reactive horses I. Heart rate, respiration rate and behavioral observations. Appl Anim Behav Sci 19, 201-214.
Morgan K, Zetterqvist M, Hassmén P, Visser EK, Rundgren M, Blokhuis HJ, 2000: Rider's Personality and the Perception of the Co-operation between Rider and Horse. EAAP 51th Annual Meeting, The Hague, p. 372.

Quadagno DM, Shryne J, Anderson C, Gorski RA, 1972: Influence of gonadal hormones on social, sexual, emergence and open field behaviour in the rat. Anim Behav 20, 732-740.

Roberts SJ, Beaver BV, 1987: The use of progestins for aggressive and for hypersexual horses. In: Robinson NE (ed.), Current Therapy in Equine Medicine-2. Saunders Company, Philadelphia, PA, pp. 129-131.

Sirois J, Fortune JE, 1990: Lengthening the bovine oestrous cycle with low levels of progesterone: a model for studying ovarian follicular dominance. Endocrinology 127, 916-924.

Spoolder HAM, Burbridge JA, Lawrence AB, Simmins PH, Edwards SA, 1996: Individual behavioural differences in pigs: intra- and intertest consistency. Appl Anim Behav Sci 49, 185-198.

Syme LA, Elphick GR, 1982/83: Heart rate and behaviour of sheep in yards. Appl Anim Ethol 9, 31-35.

Taugbøl T, Andressen Ø, Thomassen R, 1991: Mild Form of Nymphomania in the Horse: Effect of Gestagen Treatment in Racehorses. Nordic Mastitis and Reproduction meeting 24-28 July, Trondheim, Norway, pp. 115-121.

Vandenheede M, Bouissou MF, 1993: Sex differences in fear reactions in sheep. Appl Anim Behav Sci 37, 39-55.

Visser EK, 2002: Horsonality: A Study on the Personality of the Horse. Doctoral thesis, University of Utrecht, Ponsen an Looijen Wageningen.

Visser EK, van Reenen CG, Hopster $\mathrm{H}$, Schilder $\mathrm{MBH}$, Knaap JH, Barneveld A, Blokhuis HJ, 2001: Quantifying aspects of young horses' temperament: consistency of behavioural variables. Appl Anim Behav Sci 74, 241-258.

Voith VL, 1986: Principles of learning. Vet Clin North Am Equine Pract 2, 485-506.

Wolff A, Hausberger M, Le Scolan N, 1997: Experimental tests to assess emotionality in horses. Behav Proc 40, 209221.

Submitted: 14.4.2005

Author's address (for correspondence): Ylva Hedberg, Division of Comparative Reproduction, Obstetrics and Udder Health, Department of Clinical Sciences, Box 7054, SE-750 07, Uppsala, Sweden. E-mail: ylva.hedberg@kv.slu.se 